\title{
Peran Ganda Wanita Tani Dalam Usahatani Sayuran dan Peningkatan Pendapatan di Desa Nangamua Kecamatan Arut Utara Kabupaten Kotawaringin Barat
}

\section{(Double Role of Women in Vegetable Farming and Increased Income in Nangamua Village Arut Utara District Kotawaringin Barat Regency)}

\author{
Novi Nurhayati \\ Prodi Agribisnis, Fakultas Pertanian, Universitas Antakusuma \\ Jl. Iskandar No. 65 Kode pos 74112 Pangkalan Bun \\ noviuntama@gmail.com
}

\begin{abstract}
ABSTRAK
Pertanian merupakan sumber mata pencaharian utama masyarakat Indonesia. Wanita atau ibu rumah tangga di Desa Nangamua pada umumnya adalah petani sayuran. Wanita disini berperan ganda, wanita sebagai ibu rumah tangga juga sebagai tulang punggung keluarga. Tujuan penelitian ini adalah mengetahui peranan wanita dan curahan tenaga kerja wanita yang dicurahkan dalam usahatani sayuran, kontribusi pendapatan usahatani sayuran dalam pendapatan keluarga serta hubungan antara jumlah tenaga kerja yang dikeluarkan oleh wanita tani dengan jumlah pendapatan keluarga. Metode yang digunakan analisis deskriptif, analisis pendapatan dan analisis korelasi. Hasil penelitian menunjukkan wanita tani mempunyai peranan dalam usahatani sayuran, seperti penyemaian, penanaman, pemeliharaan, panen dan pasca panen, curahan tenaga kerja wanita tani dalam usahatani sayuran adalah sebesar 42,49 \% dari semua kegiatan usahatani sayuran, kontribusi pendapat usahatani sayuran dalam pendapatan keluarga adalah sebesar 33,33\% dan korelasi curahan tenaga kerja wanita dengan pendapatan usahatani sayuran, mempunyai korelasi yang posistif dengan nilai 0,70.
\end{abstract}

Kata Kunci: Wanita, peranan, usaha tani, sayuran, pendapatan.

\section{ABSTRACT}

Agriculture is the main source of livelihood for Indonesian people. Women or housewives in Nangamua Village are generally vegetable farmers. Women here play a dual role, women as housewives are also the backbone of the family. The purpose of this study was to determine the role of women and the outpouring of female labor devoted to vegetable farming, the contribution of vegetable farming income to family income and the relationship between the amount of labor spent by female farmers and the amount of family income. The method used is descriptive analysis, income analysis and correlation analysis. The results of this study were that female farmers had a role in vegetable farming, such as seeding, planting, maintaining, harvesting and post-harvest, outpouring of female farm laborers in vegetable farming was $42.49 \%$ of all vegetable farming activities, vegetable farming opinion contribution in income the family is $33.33 \%$ and the correlation of the outpouring of female labor with vegetable farming income has a positive correlation with a value of 0.70 .

Keywords: Women, roles, farming, vegetables, income.

\section{PENDAHULUAN}

Pembangunan pertanian bertujuan untuk meningkatkan pendapatan dan taraf hidup petani, pertumbuhan kesempatan kerja dan berusaha, meningkatkan gizi dan ketahanan pangan rumah tangga, dan mengentaskan kemiskinan. Pendapatan rumah tangga merupakan pendapatan yang dihasilkan oleh suami maupun istri. Wanita memiliki peluang kerja yang dapat menghasilkan pendapatan bagi rumah tangganya, sebagai upaya untuk meningkatkan pendapatan keluarga.

Pertanian merupakan sumber matapencaharian utama masyarakat Indonesia. Di Kabupaten Kotawaringin Barat jumlah penduduk yang bekerja dalam bidang pertanian sebanyak 55.150 jiwa. Prosentase jumlah penduduk yang bekerja di bidang pertanian lebih besar $(39,11 \%)$ bila dibandingkan prosentase yang bekerja dibidang yang lainnya seperti perdagangan 
(24,27\%), jasa-jasa (13,71\%), (Badan Pusat Statistik, 2017).

Desa Nangamua merupakan salah satu desa yang ada di Kecamatan Arut Utara Kabupaten Kotawaringin Barat. Jumlah penduduk di Desa Nangamua sebanyak 393 jiwa yang terdiri dari 206 jiwa laki-laki dan187 jiwa perempuan. Mata pencaharian pokok penduduk Desa Nangamua adalah sebagai petani, untuk lebih jelasnya dapat dilihat pada Tabel 1 dibawah ini.

Tabel 1. Mata pencaharian pokok penduduk Desa Nangamua

\begin{tabular}{clcc}
\hline No. & \multicolumn{1}{c}{ Mata Pencaharian Pokok } & Laki-laki (Jiwa) & Perempuan (Jiwa) \\
\hline 1. & Petani & 50 & 32 \\
2. & Pegawai Negeri Sipil & 2 & 4 \\
3. & Peternak & 5 & 6 \\
\hline
\end{tabular}

Sumber: Pemerintah Desa Nangamua (2017).

Berdasarkan pada Tabel 1, diatas jumlah penduduk yang bekerja di bidang pertanian sebanyak 50 orang laki-laki dan 32 orang perempuan, pegawai negeri sipil 2 orang lai-laki dan 4 orang perempuan, peternak 5 orang laki-laki dan 6 orang perempuan. Dari data tersebut dapat terlihat bahwa, pada umumnya masyarakat Desa Nangamua mempunya profesi sebagai seorang petani (Pemerintah Desa Nangamua, 2017).

Wanita atau ibu rumah tangga di Desa Nangamua pada umumnya adalah petani sayuran. Wanita disini berperan ganda, wanita sebagai ibu rumah tangga juga sebagai tulang punggung keluarga. Di sela-sela dalam mengurus rumah tangga, wanita tani juga berusahatani sayuran. Salah satu tujuan berusahatani ini adalah untuk menambah penghasilan keluarga. Kegiatan-kegiatan yang dapat dilakukan oleh wanita tani dalam usahatani ini diantaranya adalah menyemai, menanam, memelihara, panen dan pasca panen.

Curahan tenaga kerja yang dilakukan oleh wanita tani dalam usahatani sayuran, tidak sebanyak curahan tenaga kerja pria. Peran ganda yang dilakukan oleh wanita inilah yang menggelitik peneliti untuk meneliti, bagaimana wanita tani dalam membagi waktunya untuk berusahatani dan seberapa besar prosentase pendapatan yang dihasilkan dalam usahatani sayuran bila dibandingkan dengan total pendapatan keluarga.

Tujuan penelitian ini adalah mengetahui (i) peranan wanita dalam usahatani sayuran di Desa Nangamua Kecamatan Arut Utara Kabupaten Kotawaringin Barat, (ii) curahan tenaga kerja wanita yang dicurahkan dalam usahatani sayuran di Desa Nangamua Kecamatan Arut Utara Kabupaten Kotawaringin Barat. (iii) kontribusi pendapatan usahatani sayuran dalam pendapatan keluarga, (iv) hubungan antara jumlah tenaga kerja yang dikeluarkana oleh wanita tani dengan jumlah pendapatan keluarga.

\section{METODE PENELITIAN}

Penelitian ini dilaksanakan pada Bulan Agustus-Oktober 2018 di Desa Nangamua Kecamatan Arut Utara Kabupaten Kotawaringin Barat Provinsi Kalimantan Tengah. Data yang di gunakan dalam penelitian ini adalah data sekunder dan data primer. Data sekunder, yaitu data yang diperoleh atau dikumpulkan peneliti dari berbagai sumber yang telah ada, seperti data Badan Pusat Statistik (BPS) dan jurnaljurnal. Data primer merupakan data mentah yang didapat dilapangan. Teknik yang digunakan adalah dengan cara observasi, wawancara, diskusi terfokus dan penyebaran quisioner.

Respoden dalam penelitian ini adalah wanita yang sudah menikah (ibu rumah tangga) yang berada di wilayah Desa Nangamua Kecamatan Arut Utara. Sampel dalam penelitian ini berjumlah 32 orang wanita tani.

Analisis data yang dipergunakan untuk menjawab tujuan pertama yaitu 
peranan wanita tani dalam usahatani sayuran adalah analisis deskriptif, yaitu menjelaskan atau menjabarkan dari data yang diperoleh dilapangan.

Analisis data yang digunakan untuk menjawab tujuan kedua yaitu curahan tenaga kerja wanita dalam usahatani sayuran adalah dengan cara menghitung dan mentabulasi jumlah tenaga kerja wanita yang dicurahkan dalam usahatani sayuran.

Analisis data yang digunakan untuk menjawab tujuan ketiga yaitu kontribusi pendapatan usahatani sayuran dalam pendapatan keluarga, dengan menggunakan rumus :

$$
\text { Sumbangan pendapatan }=\frac{P n}{T p} \times 100 \%
$$

Keterangan :

$\mathrm{Pn}=$ Pendapatan usahatani sayuran

$\mathrm{Tp}=$ Total pendapatan rumah tangga petani

Pendapatan usahatani dapat dihitung dengan menggunakan rumus berikut :

Dimana :

$$
\mathbf{I}=\mathbf{T R}-\mathbf{E C}
$$

I = Pendapatan usahatani sayuran (Rp)

$\mathrm{TR}=$ Penerimaan total usahatani sayuran (Rp)

$\mathrm{EC}=$ Total biaya eksplisit usahatani sayuran (Rp)

Analisis data yang digunakan untuk menjawab tujuan keempat yaitu hubungan antara jumlah tenaga kerja yang dikeluarkana oleh wanita tani dengan jumlah pendapatan keluarga, adalah dengan menggunakan rumus :

$$
\begin{aligned}
& r=\frac{n \sum x y-\left(\sum x\right)\left(\sum y\right)}{\sqrt{\left[n \sum x^{2}-\left(\sum x\right)^{2}\right]\left[n \sum y^{2}-\left(\sum y\right)^{2}\right]}} \\
& -1 \leq r \leq 1 \\
& \text { Dimana : } \\
& \mathrm{r} \quad=\text { Koefisien korelasi } \\
& \mathrm{n} \quad=\text { Banyaknya jumlah data } \\
& \mathrm{X}=\text { Curahan Tenaga Kerja Wanita } \\
& \mathrm{Y}=\text { Pendapatan Keluarga Petani }
\end{aligned}
$$

Jika $\mathrm{r}$ semakin mendekati angka 1 atau -1 maka korelasi yang terjadi akan semakin kuat baik positif maupun negatif. Sebaliknya jika semakin mendekati 0 , maka korelasi yang terjadi semakin lemah.

\section{HASIL DAN PEMBAHASAN}

\section{Peranan Wanita Tani Dalam Usahatani Sayuran}

Dalam kehidupan bermasyarakat peran merupakan suatu aspek yang sangat penting, karena peran akan memberikan status tersendiri dalam kehidupan manusia sebagai mahluk sosial. Seorang wanita yang telah menikah mempunyai peran utama menjadi seorang ibu rumah tangga. Karena suatu keadaan, kebutuhan ekonomi dan kebiasaan hidup, wanita tani dapat berperan ganda sebagai ibu rumah tanga dan sebagai wanita yang dapat menghasilkan pendapatan dari usahatani yang dilakukannya.

Usahatani merupakan pengeloaan sumberdaya alam, tenaga kerja, modal dan skill lainnya untuk menghasilkan suatu produk pertanian secara efektif dan efesien. Usahatani sayuran yang dilakukan oleh wanita tani di Desa Nangamua, merupakan usaha yang dilakukan dalam mengisi waktu selain pekerjaan utamanya adalah sebagai ibu rumah tangga. Hal ini sesuai denga pendapat Sudarta (2010), yang menyatakan bahwa peranan perempuan disektor pertanian adalah sesuatu yang tidak terbantahkan. Dalam usahatani tanaman pangan, pembagian kerja antara pria dan wanita sangat jelas terlihat, sering dikatakan bahwa pria bekerja untuk kegiatan yang banyak menggunakan otot dan wanita bekerja untuk kegiatan yang banyak memakan waktu.

Kegiatan-kegiatan yang dapat dilakukan oleh wanita tani di Desa Nangamua dalam usahatani sayuran meliputi penyemaian, penanaman, pemeliharaan, panen dan pasca panen. Peran wanita tani dalam penyemain sayuran adalah mempersiapkan tempat untuk penyemaian, merendam benih, menyemai benih dalam tempat yang telah disediakan dan memelihara semaian bibit sampai tumbuh. Penyemain bibit sayuran merupakan langkah awal dalam budidaya sayuran, yang bertujuan untuk mengurangi kematian pada bibit tanaman. Pada umumnya penyemaian yang dilakukan dalam usahatani sayuran bertujuan untuk 
mengurangi resiko kematian bibit yang belum beradaptasi denngan lingkungan.

Setelah semaian bibit sayur telah siap untuk ditanam, maka dilakukan penanaman bibit sayuran pada lahan yang telah disiapkan. Berdasarkan hasil penelitian, penyiapan lahan dilakukan oleh suami karena penyiapan lahan merupakan kegiatan yang memerlukan tenaga yang lebih banyak.

Pemeliharaan dilakukan oleh wanita tani meliputi penyiraman pada pagi dan sore hari apabila tidak terjadi hujan, pembumbunan tanaman agar aerasi udara lebih baik, penyulaman apabila ada tanaman yang mati, pencegahan hama dan penyakit tanaman dengan melalukan pembersihan lahan disekitar tanaman.

Pemanenan dilakukan oleh wanita tani, pada saat sayuran telah siap untuk dipanen. Pasca panen yang dilakukan meliputi membersihkan tanah dari akar tanaman untuk tanaman sayuran seperti bayam dan kangkung. Memilih dan membersihkan sayuran agar sayuran yang dijual terlihat menarik dan berkualitas.

\section{Curahan Tenaga Kerja yang Dikeluarkan Oleh wanita Tani Dalam Berusahatani Sayuran}

Tenaga kerja merupakan faktor yang dapat mempengaruhi pada suatu usahatani. Tenaga kerja dalam suatu usahatani sayuran sangat diperlukan, karena denga adanya curahan tenaga kerja, usahatani dapat berjalan dengan lancar. Kekurangan tenaga kerja dapat menghambat suatu usahatani.
Hal ini sesuai dengan pendapat Shinta (2011), tenaga kerja adalah energi yang dicurahkan dalam suatu proses kegiatan untuk menghasilkan suatu produk. Dalam suatu usahatani, tenaga kerja dapat berasal dari dalam keluarga dan dari luar keluarga. Tenaga kerja yang berasal dari dalam keluarga biasanya terdiri dari ayah, ibu, anak dan saudara yang masih mempunyai hubungan darah, sedangkan tenaga kerja yang berasal dari luar keluarga merupkan masyarakat disekitar dan pada umumnya sebagai imbalannya diberikan upah atau secara bergantian saling tolong menolong.

Tenaga kerja dalam usahatani mempunyai karakteristik yang berbeda dengan curahan tenaga kerja dalam bidang yang lainya. Hal ini sesuai dengan pendapat Tohir (1991), yang menyatakan tenaga kerja dalam usaha tani mempunyai karakteristik tersendir yaitu keperluan tenaga kerja dalam usaha tani tidak kontinyu dan tidak merata, penyerapan tenaga kerja dalam usahatani sangat terbatas, dan tidak mudah dirasionalkan atau distandarkan.

Curahan jam kerja adalah waktu yang dicurahkan oleh tenaga kerja dalam kegiatan usahatani per hari per tenaga kerja, yang dalam hal ini adalah waktu yang dicurahkan wanita tani dalam berusahatani sayuran. Berdasarkan penelitian wanita tani bekerja rata-rata 4 jam sehari, mulai jam 06.00-08.00 WIB, dan pada sore hari dari jam 15.00-17.00 WIB. Berikut ini adalah curahan tenaga kerja pada usahatani sayuran di Desa Nangamua.

Tabel 2. Rata-rata curahan tenaga kerja pada usahatani sayuran Di Desa Nangamua Kecamatan Arut Utara, 2018.

\begin{tabular}{|c|c|c|c|}
\hline \multirow{2}{*}{ No. } & \multirow{2}{*}{ Tahapan Kegiatan } & \multicolumn{2}{|c|}{ Alokasi Tenaga Kerja } \\
\hline & & Pria (Jam) & Wanita (Jam) \\
\hline 1. & Persiapan Lahan & 40 & 9 \\
\hline 2. & Penyemaian Benih & 0 & 4 \\
\hline 3. & Pemeliharaan Bibit & 7 & 7 \\
\hline 6. & Penanaman & 6 & 8 \\
\hline 7. & Penyiangan & 7 & 9 \\
\hline 8. & Pemberantasan HPT & 8 & 4 \\
\hline 9. & Pengairan & 35 & 25 \\
\hline 10. & Pemupukan & 4 & 2 \\
\hline 11. & Pemanenan & 2 & 6 \\
\hline 12. & Pasca Panen & 2 & 8 \\
\hline & Jumlah & 111 & 82 \\
\hline
\end{tabular}


Berdasarkan Tabel 2, rata-rata curahan tenaga kerja pria adalah 111 jam, sedangkan curahan tenaga kerja wanita adalah 82 jam. Perbandingan dengan tenaga kerja pria, curahan tenaga kerja wanita paling banyak digunakan pada pasca panen sebesar 4 : 1 . Tujuan dari pasca panen adalah mempertahankan mutu produk sayuran agar tetap prima sampai ke tangan konsumen, menekan kehilangan hasil karena kerusakan dan penyusutan, serta memperpanjang daya simpan dan meningkatkan nilai ekonomis sayuran. Kegiatan pasca panen ini meliputi pembersihan tanah yang masih melekat, memilih sayuran yang berkualitas, menimbang atau mengikat sayuran. Hal ini sesuai dengan pendapat Balai Besar Pelatihan Pertanian Lembang (2015), kegiatan pasca panen sayuran meliputi pengumpulan, sortasi pembersihan, pengemasan penyimpanan dan transportasi.

Prosentase kontribusi curahan tenaga kerja wanita tani dalam usahatani sayuran dapat dilihat pada Tabel 3, dibawah ini.

Tabel 3. Prosentase Curahan Tenaga Kerja dalam Usahatani Sayuran

\begin{tabular}{ccccc}
\hline No. & & Curahan Tenaga Kerja & HKO (jam) & Prosentase $(\%)$ \\
\hline 1. & Pria & & 111 & 57,51 \\
2. & Wanita & & 82 & 42,49 \\
\hline & & Jumlah & 193 & 100 \\
\hline
\end{tabular}

Berdasakan Tabel 3 diatas, prosentase kontribusi curahan tenagan kerja wanita tani dalam usahatani sayuran adalah sebesar $42,49 \%$. Dari data diatas terlihat bahwa wanita tani mempunyai kontribusi dalam hal tenaga kerja yang cukup besar dalam usahatani sayuran.

\section{Pendapatan Usahatani Sayuran}

Analisis usahatani merupakan suatu analisa yang dipergunakan untuk mengetahui berapa produksi yang dihasilkan, tenaga yang dipergunakan, biaya yang dikeluarkan dan berapa pendapatan yang dihasilkan.

Pendapatan merupakan hasil dari penerimaan usahatani dikurangi dengan total biaya yang eksplisit. Hal ini sesuai dengan pendapat Hanafie (2010), yang menyatakan pendapatan/keuntungan adalah selisih antara penerimaan total dengan biaya yang benarbenar dikeluarkan.

Berdasarkan hasil penelitian rata-rata penerimaan yang dihasilkan dari usahatani sayuran ini adalah sebesar Rp. 3.000.000.,setiap bulannya. Penerimaan ini berasal dari hasil kali antara jumlah produksi yang dihasilkan dengan harga jual. Penerimaan disebut juga dengan pendapatan kotor, karena pada penerimaan ini semua biaya tidak diperhitungkan sama sekali, hal ini sesuai dengan pendapat Suratiyah (2009) yang menyatakan bahwa penerimaan adalah jumlah produksi dikalikan dengan harga produksi dengan satuan rupiah.

Biaya eksplisit adalah biaya yang dikeluarkan dalam berusahatani dan dapat dihitung nilainya. Dalam berusahatani sayuran ini, biaya eksplisit seperti biaya yang dikeluarkan untuk pembelian pestisida, bibit, pupuk organik dan pupuk anorganik, cangkul, dan gembor. Rata-rata biaya eksplisit yang dikeluarkan dalam berusahatani sayuran adalah sebesar Rp.1.500.000.,

Rata-rata pendapatan petani sayur di desa Nangamua adalah sebesar Rp. Rp. 1.500.000., yang berasal dari selisih antara penerimaan dengan biaya-biaya yang dikeluarkan (Rp. 3.000.000 - Rp. 1.500.000). Disela-sela dalam berusahatani, petani juga bekerja seperti sebagai perangkat desa, membuka warung, berkebun, mencari ikan, dan beternak. Rata-rata pendapata total keluarga petani adalah sebesar $\mathrm{Rp}$. 4.500.000.,.

Sumbangan pendapatan petani sayuran dalam pendapatan keluarga petani adalah sebesar $33,33 \%$ dari seluruh pendapatan keluarga petani. Hal ini berarti pendapatan dari usahatani menyumbang sebesar 33,33\% dari seluruh pendapatan keluarga petani. Sumbangan pendapatan dari usahatani sayuran sangat membantu perekonomian keluarga dalam memenuhi 
kebutuhan rumah tangga petani di Desa Nangamua.

\section{Korelasi Curahan Tenaga Kerja Dengan Pendapatan Keluarga}

Berdasarkan hasil analisis korelasi antara curahan tenaga kerja wanita dengan pendapatan keluarga mempunyai hubungan korelasi yang positif dengan nilai sebesar 0,70 . Ini berarti bahwa curahan tenaga kerja wanita mempunyai hubungan yang cukup berarti dengan pendapatan keluarga petani. Hal ini sesuai dengan pendapat Hasan (2009), yang menyatakan bahwa apabila nilai korelasi (r) sebesar $0,40<\mathrm{KK} \leq 0,70$, berarti bahwa korelasi yang cukup berarti.

Hasil korelasi yang tinggi dengan nilai 0,70 ini membuktikan bahwa curahan tenaga kerja wanita mempunyai hubungan yang cukup berarti dalam meningkatkan pendapatan keluarga petani. Hubungan yang cukup berarti antara curahan tenaga kerja wanita dengan pendapatan petani, karena dari usaha tani sayuran yang dilakukan dapat menambah pendapatan keluarga dalam memenuhi kebutuhan keluarga, selain itu curahan tenaga kerja wanita tani dalam usahatani sayuran ini, membantu suami atau kepala keluarga dalam berusahatani, seperti dalam penyemain, penanaman, pemeliharaan, panen dan pasca panen.

\section{KESIMPULAN}

Berdasarkan hasil dan pembahasan dapat diambil kesimpulan sebagai berikut : peranan wanita tani dalam usahatani sayuran meliputi penyemaian, penanaman, pemeliharaan, panen dan pasca panen; tenaga kerja wanita tani yang dicurahkan dalam usahatani sayuran rata-rata 4 jam sehari dengan kontribusi terbesar pada kegiatan pasca panen serta menyumbangkan $42,49 \%$ dari semua kegiatan usahatani sayuran; pendapatan usahatani sayuran sebesar Rp. 1.500.000., yang mempunyai kontribusi terhadap pendapatan keluarga sebesar $33,33 \%$; korelasi curahan tenaga kerja wanita dengan pendapatan usahatani sayuran mempunyai korelasi yang cukup berarti (membantu pendapatan keluarga) dengan nilai 0,70 .

\section{DAFTAR PUSTAKA}

Badan Pusat statisik, 2017. Kotawaringin Barat Dalam Angka 2017. Badan Pusat Statistik Kabupaten Kotawaringin Barat.

Pemerintah Desa Nangamua, 2017. Profil Desa Nangamua Tahun 2017. Kecamatan Arut Selatan. Kabupaten Kotawaringin Barat.

Sudarta, W. 2010. Peran Wanita dalam Pembangunan Berwawasan Gender. Jurusan Sosial Ekonomi Pertanian, Fakultas Pertanian Universitas Udayana. www.pswunud.go.id, diakses pada 2 Oktober 2018.

Shinta, A. 2011. Ilmu Usahatani. Universitas Brawijaya Press. Malang.

Tohir, K. A. 1991. Seuntai Pengetahuan Usahatani Indonesia. Rineka Cipta. Jakarta.

Balai Besar Pelatihan Pertanian Lembang. 2015. Pasca Panen sayuran. www.bbpp-lembang. go.id Diakses 1 Oktober 2018.

Hanafie, R. 2010. Pengantar Ekonomi Pertanian. Andi. Yogyakarta.

Suratiyah, K. 2009. Ilmu Usahatani. Penebar Swadaya. Jakarta.

Hasan, I. 2009. Pokok-Pokok Materi Statitik I (Statistik Deskriptif). Edisi Kedua. PT. Bumi Aksara. Jakarta. 